\title{
Density of Bismuth Boro Zinc Glasses Using Machine Learning Techniques
}

\author{
Shaik Amer Ahmed ${ }^{1} \cdot$ Shaik Rajiya $^{2} \cdot$ M. A. Samee ${ }^{2} \cdot$ Shaik Kareem Ahmmad $^{3} \cdot$ Kaleem Ahmed Jaleeli $^{1}$
}

Received: 18 September 2021 / Accepted: 3 December 2021 / Published online: 18 January 2022

(c) The Author(s), under exclusive licence to Springer Science+Business Media, LLC, part of Springer Nature 2021

\begin{abstract}
Machine learning techniques have been employed to predict the glass densities of $\mathrm{xBi}_{2} \mathrm{O}_{3}-(70-\mathrm{x}) \mathrm{B}_{2} \mathrm{O}_{3}-20 \mathrm{Li}_{2} \mathrm{O}-5 \mathrm{Sb}_{2} \mathrm{O}_{3}-$ $5 \mathrm{ZnO}$ glasses using a data set of 2000 various $\mathrm{B}_{2} \mathrm{O}_{3}$ rich glasses using their chemical composition and ionic radius. The experimental density of present glasses strongly depends on $\mathrm{Bi}_{2} \mathrm{O}_{3}$ content which is increasing with bismuth content. The increasing density in bismuth doped glasses because the $\mathrm{BO}_{3}$ are converted into $\mathrm{BO}_{4}$ units, and besides $\mathrm{BO}_{3}$ units are less heavy than the $\mathrm{BO}_{4}$ units. The FTIR studies also confirm that the intensity of $\mathrm{B}-\mathrm{O}-\mathrm{B}$ bond decreasing with increasing $\mathrm{Bi}_{2} \mathrm{O}_{3}$ content which suggested that $\mathrm{B}-\mathrm{O}-\mathrm{B}$ bond in bond ring isolated to $\mathrm{BO}_{3}$ units transformed into $\mathrm{BO}_{4}$ units. In Raman Spectra the stretching vibrations of $\mathrm{BO}_{4}$ units shifting towards higher wavelengths with increasing $\mathrm{Bi}_{2} \mathrm{O}_{3}$ content. This shifting conforms that there is a structural changes in the glass-matrix and borate units converting from $\mathrm{BO}_{3}$ to $\mathrm{BO}_{4}$ units. The prepared glasses along with $\mathrm{B}_{2} \mathrm{O}_{3}$ rich glass data set train on various $\mathrm{AI}$ model such as gradient descent, Random Forest regression and Neural Networks to predict present density of glasses. Among the various models RF regression analysis model is successfully acceptable for the glass data with the highest $R^{2}$ value 0.983 which end result conform that the predicted and experimental values correlated. ANNs stood the effective technique in prediction of glass density with the optimum performance resulting with Tanh as the activation function $\left(R^{2}=0.950\right)$. The minimum cost 0.018 obtained in the case of gradient decent function which also shows the better performance of regression model.
\end{abstract}

Keywords Bismuth borate zinc glasses $\cdot$ ML density model $\cdot$ FTIR $\cdot$ Density prediction

\section{Introduction}

Glasses containing metal oxide such as bismuth and Zinc got the eye of the researcher owing to its wide-range of uses in the field of glass-ceramics such as in thermal sensors, mechanical sensors, reflecting windows, optic apparatuses etc. They possess a cut-off infrared (IR) wavelength of larger range, and non-linear optic-susceptibility of third-order and these properties are ideal to use it as an IR transmission devices, ultrafast optical switches, and opto-photonic devices [1-8].

Shaik Kareem Ahmmad

kareem.ahmed@mjcollege.ac.in

1 Department of Physics, Nizam College, Osmania University, Hyderabad, India

2 Department of Physics, College of Science, Osmania University, Hyderabad, India

3 Department of Physics, Muffakahm Jah College of Engineering and Technology, Hyderabad, India
Doweidar et al. [9] prepared Zinc Bismuth Borate glasses and investigated mechanical properties and Debye temperature by measuring the sound velocities (VL and Vs). The IR spectroscopic studies reveals that when $\mathrm{ZnO} / \mathrm{BaO}$ is merged into bismuth borate network, forming $\mathrm{BO}_{4}$-units and $\mathrm{BiO}_{6}$ units formed in glass structure due to the existence $\mathrm{Bi}_{2} \mathrm{O}_{3}$ units only. The variation in the physical properties like number of atoms in the glass structure and molar volume with respect to $\mathrm{ZnO} / \mathrm{BaO}$ content ratio discloses that $\mathrm{BO}_{4}$ units associated to $\mathrm{R}^{2+}$ cations are heavier than those associated to positive sites in the Bismuth oxide glass network.

Saddeek [10] investigated mechanical properties with measured density of the glass system $\mathrm{B}_{2} \mathrm{O}_{3}-\mathrm{Bi}_{2} \mathrm{O}_{3}-\mathrm{Li}_{2} \mathrm{O}$ using ultrasonic pulse echo technique and studied the elastic moduli of the bismuth borate glasses and expressed the relation between the number of network bonds in the structure and the cross-link density in the glasses and also stated that the average ring size of the network has been modified with the addition of bismuth. 
According to many researchers, mostly the glass densities have been measured from the composition of the particular glasses only [11-13]. To understand the elastic behavior of the glasses by using composition of the network like ceramic-materials were utilized to understand the glass pattern [14]. Several ML-models to measure the density precisely through composition-based parameters such as packing fraction and ionic radii to get least error were also reported [15].

In accordance with recent studies on machine learning models to predict glass properties, they have used huge datasets making them "data-driven" models that successfully derive a correlation between the input and the output variables [11-15]. These models directly map the chemical composition of the glass to their respective properties. It would be logical if the behavior of glass properties are defined based on an 'intermediate' factor that is in turn defined by the atomic network of the glass composition. Recently, several Artificial Intelligence techniques have been successfully applied in predicting glass density in relation to 'Atomic Packing Fraction' factor used in the Makishima Mackenzie-model using a dataset compiled from published works which resulted in efficient density prediction correlating to the experimental results [16]. Recently, an improvement in the packing fraction model [17] was proposed with a new packing factor to account for the drawbacks in the previous APF-model based on the oxygen-atom packing fraction called the "Rigid-Unit Packing Fraction" (RUPF).

In the present work, the machine learning density model is applied to prepared $\mathrm{x} \mathrm{Bi}_{2} \mathrm{O}_{3}-(70-\mathrm{x})$ $\mathrm{B}_{2} \mathrm{O}_{3}-20 \mathrm{Li}_{2} \mathrm{O}-5 \mathrm{Sb}_{2} \mathrm{O}_{3}-5 \mathrm{ZnO}(\mathrm{x}=0,2.5,5,7.5$ and $10 \mathrm{~mol} \%$ ) glasses and density of glasses predicted through it chemical composition and ionic radii. A data set of 2000 B2O3-rich glass with various compositions was compiled from scholarly publications to predict glass density.

\section{Experimental}

The present glass composition $\mathrm{xBi}_{2} \mathrm{O}_{3}-(70-\mathrm{x})$ $\mathrm{B}_{2} \mathrm{O}_{3}-20 \mathrm{Li}_{2} \mathrm{O}-5 \mathrm{Sb}_{2} \mathrm{O}_{3}-5 \mathrm{ZnO}(\mathrm{x}=0,2.5,5,7.5$ and $10 \mathrm{~mol} \%$ ) was prepared by the popular melt quenching method. To obtain pure glasses, $99.99 \%$ highly pure oxide (all Sigma Aldrich) Boron dioxide $\left(\mathrm{B}_{2} \mathrm{O}_{3}\right)$, Bismuth oxide $\left(\mathrm{Bi}_{2} \mathrm{O}_{3}\right)$, Zinc Oxide $(\mathrm{ZnO})$, Antimony trioxide $\left(\mathrm{Sb}_{2} \mathrm{O}_{3}\right)$ and lithium carbonate $\left(\mathrm{Li}_{2} \mathrm{CO}_{3}\right)$ were taken in suitable amount. A $10 \mathrm{~g}$ mixture of oxides were taken in porcelain crucible and mixed frequently for proper mixing and kept it in a preheated furnace at the temperature of $1100-1200{ }^{\circ} \mathrm{C}$ for about $1 \mathrm{~h}$. During the heating process in order to get homogeneity, the glass liquid was frequently swirled. In order to get desired glasses, the liquefied glassy compound were casted in a stainless steel mould and quenched at $200{ }^{\circ} \mathrm{C}$. The glass specimens were prepared in different forms like disc-shaped, square-shaped and rod-shaped. Post quenching, the prepared glass samples were annealed at $200{ }^{\circ} \mathrm{C}$ for $24 \mathrm{~h}$ to remove stress and strain. XRD technique was carried out by using the diffractometer (model, Phillips $\mathrm{PW} 1830 \mathrm{Cu}, \mathrm{K} \alpha$ radiation of $1.54 \AA$ wavelengths, from $10^{\circ}$ to $80^{\circ}$ ) in order to conform the amorphous nature of the prepared glasses illustrated Fig. 1. Bruker Optics (Tensor 27, Germany) absorption spectrometer was used to carry out infrared studies of the present glasses in the form of thin pellets mixed with $\mathrm{KBr}$ in the range $4000-200 \mathrm{~cm}^{-1}$. Raman spectrometer from WITec (Germany) equipped with a confocal aperture used to record micro-Raman measurements of prepared glasses of $1 \mathrm{~mm}$ thickness and $1 \mathrm{~cm}$ in diameter. Raman spectrum was studied for wavelength ranging $200-2000 \mathrm{~cm}^{-1}$. An Olympus LM-Plan microscope objective (NIR optimized), a grating of 1800 lines/mm along with an external CCD-detector were utilized. A precision of $\sim 0.3 \mathrm{~cm}^{-1}$ is maintained while measuring the Raman shifts with a $1 \mathrm{~cm}^{-1}$ spectral resolution order.

\section{Data Set}

A wide range of 2000 distinct $\mathrm{B}_{2} \mathrm{O}_{3}$ rich glasses configurations were sourced from reputed journals with their laboratory tested density values. This dataset can be easily obtainable for observation purposes on the website www.nridg.com designed by the author. This distinct database came into existence with the authors intense efforts, by analyzing a wide range of reputed journals of various academic publications so as to arrive at the accurate Artificial Intelligence model.

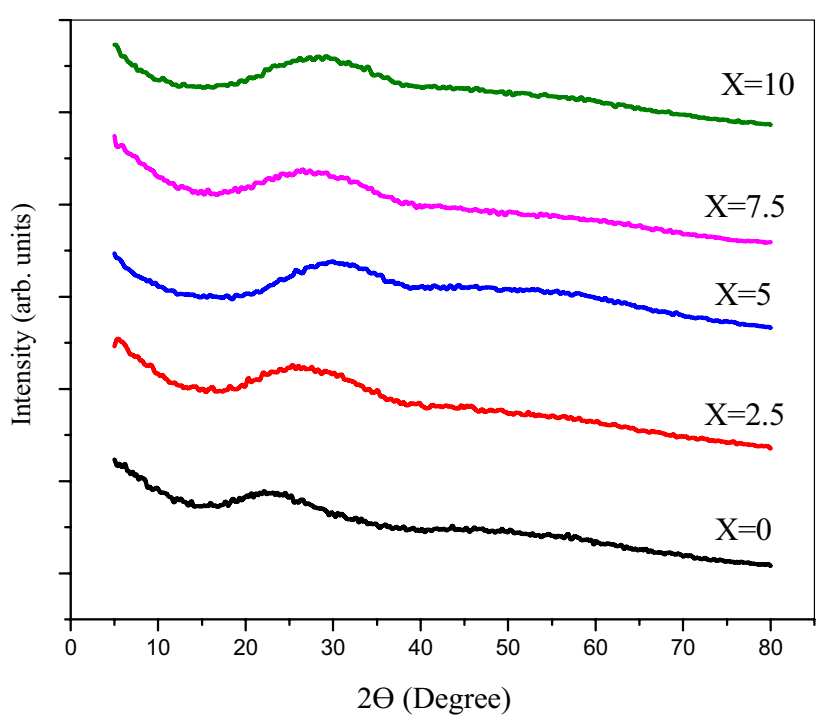

Fig. 1 XRD spectra of $\mathrm{xBi}_{2} \mathrm{O}_{3}-(70-\mathrm{x}) \mathrm{B}_{2} \mathrm{O}_{3}-20 \mathrm{Li}_{2} \mathrm{O}-5 \mathrm{Sb}_{2} \mathrm{O}_{3}-5 \mathrm{ZnO}$ glasses 


\section{Results and Discussion}

\subsection{Density}

The density was calculated from the following relation.

$\rho=\frac{W_{\mathrm{A}}}{W_{\mathrm{A}}-W_{\mathrm{L}}} \times \rho_{\mathrm{L}}$

where $\mathrm{W}_{\mathrm{A}}$ and $\mathrm{W}_{\mathrm{L}}$ are weight of the glass sample in air and sample immersed in Xylene liquid simultaneously. $\rho_{L}$ is the density of immersed liquid at room temperature $\left(\rho_{L}=0.86\right)$. Molar volume $\left(\mathrm{V}_{\mathrm{m}}\right)$ is explained as the volumetric area occupied by one mole of glass, and is given by

$V_{\mathrm{m}}=\frac{\text { molecular weight of glass }(\mathrm{MW})}{\operatorname{density}(\rho)}$

The oxygen packing density (OPD) is defined as the no of packing of the oxides present in the network of the glass and is given by

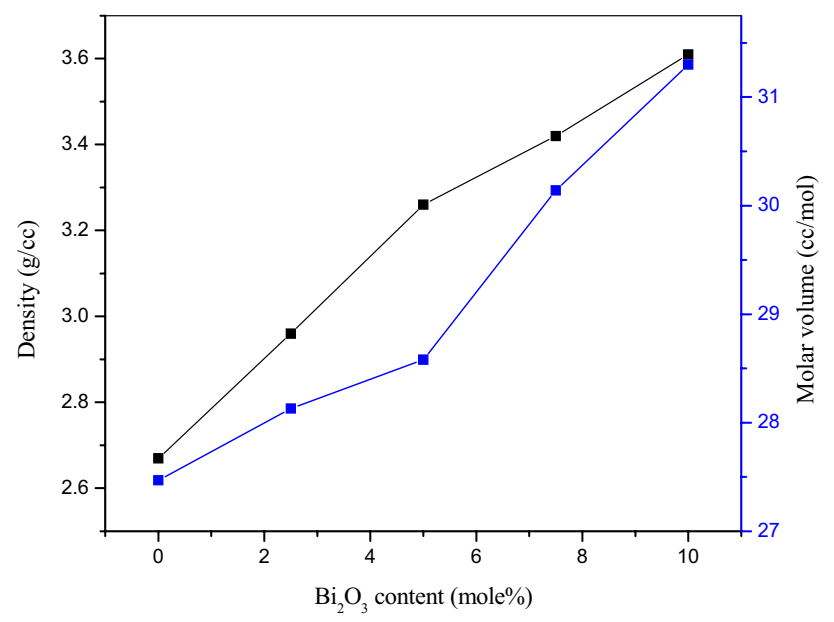

Fig. 2 Density and molar volume of present glasses
$\mathrm{OPD}=\frac{1000 n}{V_{\mathrm{m}}}$

where $n$ is number of oxygens present in the glass composition.

Figure 2 represents the variation in experimental density and associated molar volume with variation of Bismuth content. Figure 2 shows that measured density $(\rho)$ increases from 2.671 to $3.610(\mathrm{gram} / \mathrm{cc})$ and the molar volume $\left(V_{\mathrm{m}}\right)$ also climbs from 27.46 to 31.30 (cc/mol) with increasing $\mathrm{Bi}_{2} \mathrm{O}_{3}$ content. The calculated density, oxygen packing density values are tabulated in Table 1 .

Saddeek [10] reported that in ternary system $25 \mathrm{Li}_{2} \mathrm{O}-(75-\mathrm{x}) \mathrm{B}_{2} \mathrm{O}_{3}-\mathrm{xBi}_{2} \mathrm{O}_{3}$ density and molar volume are increasing with increase in modifier content. With the addition of bismuth in the glass structure the NBOs result increases and as a result the density of the glass increases. Doweidar et al. [9] investigated the physical properties of $\mathrm{xZnO}-30 \mathrm{Bi}_{2} \mathrm{O}_{3}-(70-\mathrm{x}) \mathrm{B}_{2} \mathrm{O}_{3}$ glasses and they found that the density increases from 4.99 to $5.50 \mathrm{~g} / \mathrm{cc}$ when $\mathrm{ZnO}$ oxide is introduced into the glass network by structural changes. The increase in density of the present glasses is due to the substitution of heavier $\mathrm{Bi}_{2} \mathrm{O}_{3}$ molecules $(\mathrm{M}=465.96 \mathrm{~g} / \mathrm{mol})$ for lighter $\mathrm{B}_{2} \mathrm{O}_{3}$ molecules $(\mathrm{M}=69.62 \mathrm{~g} / \mathrm{mol})$ and the addition of network modifiers like bismuth in the borate structure leads to increase of the Non bridging oxygen in the glass structure which results in the increase of density of the glass [18]. Because a significant proportion of oxygen ions are present in the glass structure, there is an incorporation of heavier $\mathrm{Bi}^{3+}$ ions in the glass structure which leads to structural alteration. In bismuth doped glasses, the oxygen ions are converted from $\mathrm{BO}_{3}$ to $\mathrm{BO}_{4}$ structural units, the structural unit $\mathrm{BO}_{4}$ in a network is heavier than the $\mathrm{BO}_{3}$ units in the same network, and hence the increase in density of the glass [19]. The conversion of $\mathrm{BO}_{3}$ units into $\mathrm{BO}_{4}$ units when $\mathrm{Bi}_{2} \mathrm{O}_{3}$ content increases explained as follows.

Generally in $\mathrm{B}_{2} \mathrm{O}_{3}$ based glasses Boron exists mainly in two types of structural units, one of which is trigonal $\left[\mathrm{BO}_{3}\right]$ called bridging oxygens and the other is tetrahedral $\left[\mathrm{BO}_{4}\right]$ units called non bridging oxygens. When $\mathrm{Bi}_{2} \mathrm{O}_{3}$ is introduced

Table 1 Predicted density of various ML models of $x \mathrm{Bi}_{2} \mathrm{O}_{3}-(70-\mathrm{x}) \mathrm{B}_{2} \mathrm{O}_{3}-20 \mathrm{Li}_{2} \mathrm{O}-5 \mathrm{Sb}_{2} \mathrm{O}_{3}-5 \mathrm{ZnO}$ glasses

\begin{tabular}{|c|c|c|c|c|c|c|c|c|c|}
\hline \multirow[t]{3}{*}{$\mathrm{Bi}_{2} \mathrm{O}_{3} \mathrm{~mol} \%$} & \multirow[t]{3}{*}{ Exp. density } & \multicolumn{6}{|l|}{ Predicted density } & \multicolumn{2}{|c|}{$\begin{array}{l}\text { Boron separa- } \\
\text { tion }\end{array}$} \\
\hline & & \multirow[t]{2}{*}{ Gradient decent } & \multirow[t]{2}{*}{ Random forest } & \multicolumn{4}{|c|}{ Artificial Neural network } & \multirow[t]{2}{*}{$\mathrm{BO}_{3}$} & \multirow[t]{2}{*}{$\mathrm{BO}_{4}$} \\
\hline & & & & Sigmoid & $\mathrm{ReLu}$ & Identity & $\tanh$ & & \\
\hline$X=0$ & 2.671 & 2.630 & 2.650 & 2.620 & 2.591 & 2.590 & 2.630 & 0.13 & 0.18 \\
\hline$X=2.5$ & 2.960 & 2.905 & 2.925 & 2.895 & 2.866 & 2.852 & 2.919 & 0.09 & 0.21 \\
\hline$X=5$ & 3.261 & 3.181 & 3.201 & 3.171 & 3.142 & 3.141 & 3.199 & 0.05 & 0.25 \\
\hline$X=7.5$ & 3.423 & 3.453 & 3.400 & 3.370 & 3.341 & 3.340 & 3.350 & 0 & 0.27 \\
\hline$X=10$ & 3.610 & 3.721 & 3.570 & 3.540 & 3.511 & 3.500 & 3.490 & 0 & 0.28 \\
\hline
\end{tabular}


into the glass network it produces a low crystallization and form stable glasses which are moisture resistant [20]. The network modifier $\mathrm{Li}_{2} \mathrm{O}$ in the current glasses convert some triangular units $\left[\mathrm{BO}_{3}\right]$ to tetrahedral units $\left[\mathrm{BO}_{4}\right]$ which are then integrated in complex cylclic groups as $\mathrm{Di}-$, Tri-, Tetraor Penta-Borate groups [21]. We know that $\mathrm{Bi}_{2} \mathrm{O}_{3}$ being a conditional glass former, $\mathrm{Bi}^{3+}$ possesses a high polarizability thus creating a solid structural effect in the glass network. In the present study the calcinations of Boron separation in $\mathrm{BO}_{3}$ and $\mathrm{BO}_{4}$ units are also calculated and the values are tabulated in Table 1. From the above table it has been observed that the Boron separation in $\mathrm{BO}_{4}$ units increases with $\mathrm{Bi}_{2} \mathrm{O}_{3}$ content, whereas the separation decreases in $\mathrm{BO}_{3}$ units. This variation results the $\mathrm{BO}_{3}$ units to transformed into $\mathrm{BO}_{4}$ units in the present glasses. The conformation of conversion of units in the present study is also confirmed by the FITR and Raman and the details analysis is explained as follows:

FTIR absorbance spectra was captured in the wave number ranging $400-1700 \mathrm{~cm}^{-1}$ with an illustration in Fig. 3. The de-convoluted spectra of all the glass samples are illustrated in Fig. 4. The de-convoluted parameters and band assignments are presented in Tables 2 and 3 . The present IR spectra was de-convoluted with 6 Gaussian peaks for better understanding the deconvolution process [22-25] and structural changes in the glass network.

In general, there are four principal bands around $500 \mathrm{~cm}^{-1}, 680 \mathrm{~cm}^{-1}, 1050 \mathrm{~cm}^{-1}, 1397 \mathrm{~cm}^{-1}$ with a shoulder of $950 \mathrm{~cm}^{-1}$ and $1260 \mathrm{~cm}^{-1}$ observed in all the prepared glasses. In the present IR spectra, as $\mathrm{Bi}_{2} \mathrm{O}_{3}$ matter climbs, the band at $510 \mathrm{~cm}^{-1}$ contributing to the $\mathrm{Bi}-\mathrm{O}-\mathrm{Bi}$ vibrations of distorted $\left[\mathrm{BiO}_{6}\right]$ octahedral units [26] and this peak shifts to lower wave numbers. The $\mathrm{BiO}_{3}$ polyhedra vibration band

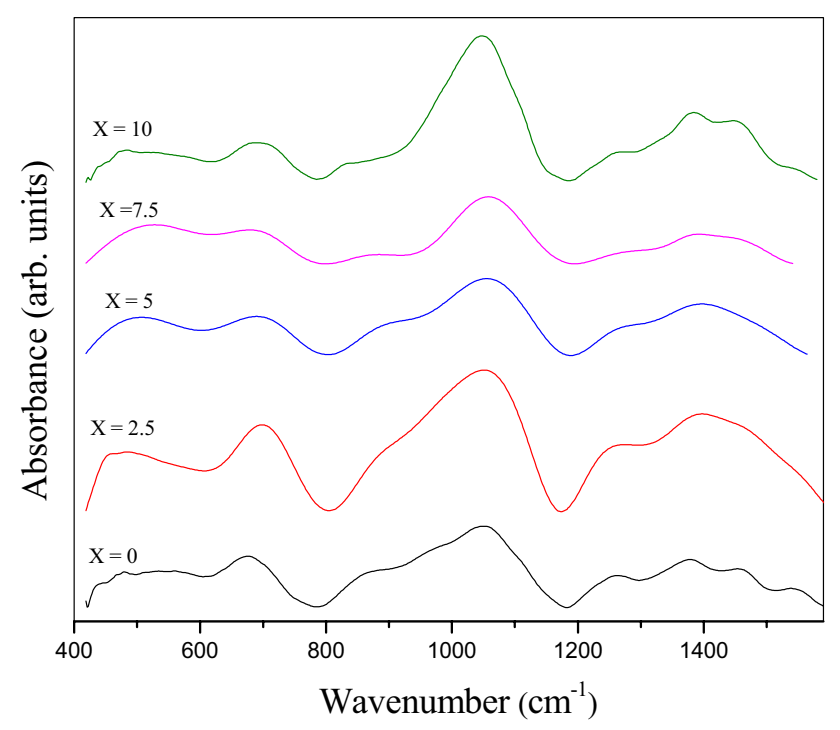

Fig. 3 FTIR spectra of present glasses does not appear in the IR absorption as it is around $840 \mathrm{~cm}^{-1}$ $[26,27]$. Hence only the $\left[\mathrm{BiO}_{6}\right]$ octahedral units contribute to the bismuth structure present in the glasses. There is a change in wave numbers from $674 \mathrm{~cm}^{-1}$ to $694 \mathrm{~cm}^{-1}$ and is increasing with $\mathrm{Bi}_{2} \mathrm{O}_{3}$ content which is attributed to $\mathrm{B}-\mathrm{O}-\mathrm{B}$ in $\left[\mathrm{BO}_{3}\right]$ units [26]. The electrostatic field of the strongly polarizing $\mathrm{Bi}^{2+}$ ions may create this shift. The rise in $\mathrm{B}_{2} \mathrm{O}_{3}$ content increases the density of the electron cloud about $\mathrm{BO}_{3}$ oxygen units, leading to increasing roll-torque of $\mathrm{B}-\mathrm{O}-\mathrm{B}$ band therefore adds to bending vibrations of $\mathrm{B}-\mathrm{O}-\mathrm{B}$ band shifting towards a greater wave-number.

The band at above $691 \mathrm{~cm}^{-1}$ is attributable to the bending vibrations of Boro-Oxy-Boro bonds in boroxole rings. Kaur et al. [28] reported the band being at $693 \mathrm{~cm}^{-1}$ credit to the same vibrations of B-O-B bonds. Sayyed et al. [29] observed a strong bond around $635 \mathrm{~cm}^{-1}$ which is due to the $\mathrm{B}-\mathrm{O}-\mathrm{B}$ bending vibrations. Rani et al. [20] reported a band around $700 \mathrm{~cm}^{-1}$ is attributed to the bending vibrations of $\mathrm{B}-\mathrm{O}-\mathrm{B}$ in $\mathrm{BO}_{3}$ units. The band in the range $937-983 \mathrm{~cm}^{-1}$ of the IR spectra confirms that the presence of $\left[\mathrm{BO}_{4}\right]$ units point toward the addition of $\mathrm{Bi}_{2} \mathrm{O}_{3}$ to $\mathrm{B}_{2} \mathrm{O}_{3}$ which causes a progressive conversion of $\left[\mathrm{BO}_{3}\right]$ units to $\left[\mathrm{BO}_{4}\right]$ units [26]. Cheng et al. [26] observed the stretching vibrations of $\left[\mathrm{BO}_{4}\right]$ units in $\mathrm{Bi}_{2} \mathrm{O}_{3}-\mathrm{B}_{2} \mathrm{O}_{3}$ glasses in the spectral range of $900-950 \mathrm{~cm}^{-1}$ which confirm the conversion of structural units form $\mathrm{BO}_{3}$ units to $\mathrm{BO}_{4}$. The IR bands observed ranging within 1051-1056 $\mathrm{cm}^{-1}$ are attributed to Boron-Oxygen stretching vibrations on $\mathrm{BO}_{4}$ units thus form tri-borate, tetraborate, and penta-borate groups, while the bands detected at $1263-1282 \mathrm{~cm}^{-1}$ are assigned to Boron-Oxygen stretching vibrations of $\mathrm{BO}_{3}$, while $1397-1408 \mathrm{~cm}^{-1}$ are allocated to similar vibrations of $\mathrm{B}-\mathrm{O}$ of trigonal $\left(\mathrm{BO}_{3}\right)^{3-}$ units in meta-, pyro-, and ortho-borates [20, 30]. The derived area and center of the above two band are tabulated in Table 2 . From Table 2 it has been observed that the relative area of these two band marginally increases with increase in $\mathrm{Bi}_{2} \mathrm{O}_{3}$ content. Rani et al. [20] reported the IR spectra of lithium bismuth borate zinc glasses and observed that the area of both the bands at 1020 and $1384 \mathrm{~cm}^{-1}$ increases with increasing the $\mathrm{Bi}_{2} \mathrm{O}_{3}$ content and also reported a redshift in band $1020 \mathrm{~cm}^{-1}$ when $\mathrm{Bi}_{2} \mathrm{O}_{3}$ content increases. The present study also noted that when $\mathrm{Bi}_{2} \mathrm{O}_{3}$ content increases, a red shift in the band range $1056-1051 \mathrm{~cm}^{-1}$ is observed which is attributable to the transformation of $\mathrm{BO}_{3}$ to $\mathrm{BO}_{4}$ structural units.

The computation of $\mathrm{B}_{2} \mathrm{O}_{3}$ structural groups can be explained by the calculations of four coordinate $\mathrm{B}$-atoms $\mathrm{N}_{4}$ and three coordinate $\mathrm{B}$-atoms $\mathrm{N}_{3}$ as [22]:

$N_{4}=\left[A_{4}\right] /\left\{\left[A_{3}\right]+\left[A_{4}\right]\right\}$ and $N_{3}=1-N_{4}$

where $A_{3}$ and $A_{4}$ denotes the areas of $\mathrm{BO}_{3}$ and $\mathrm{BO}_{4}$ units respectively. 

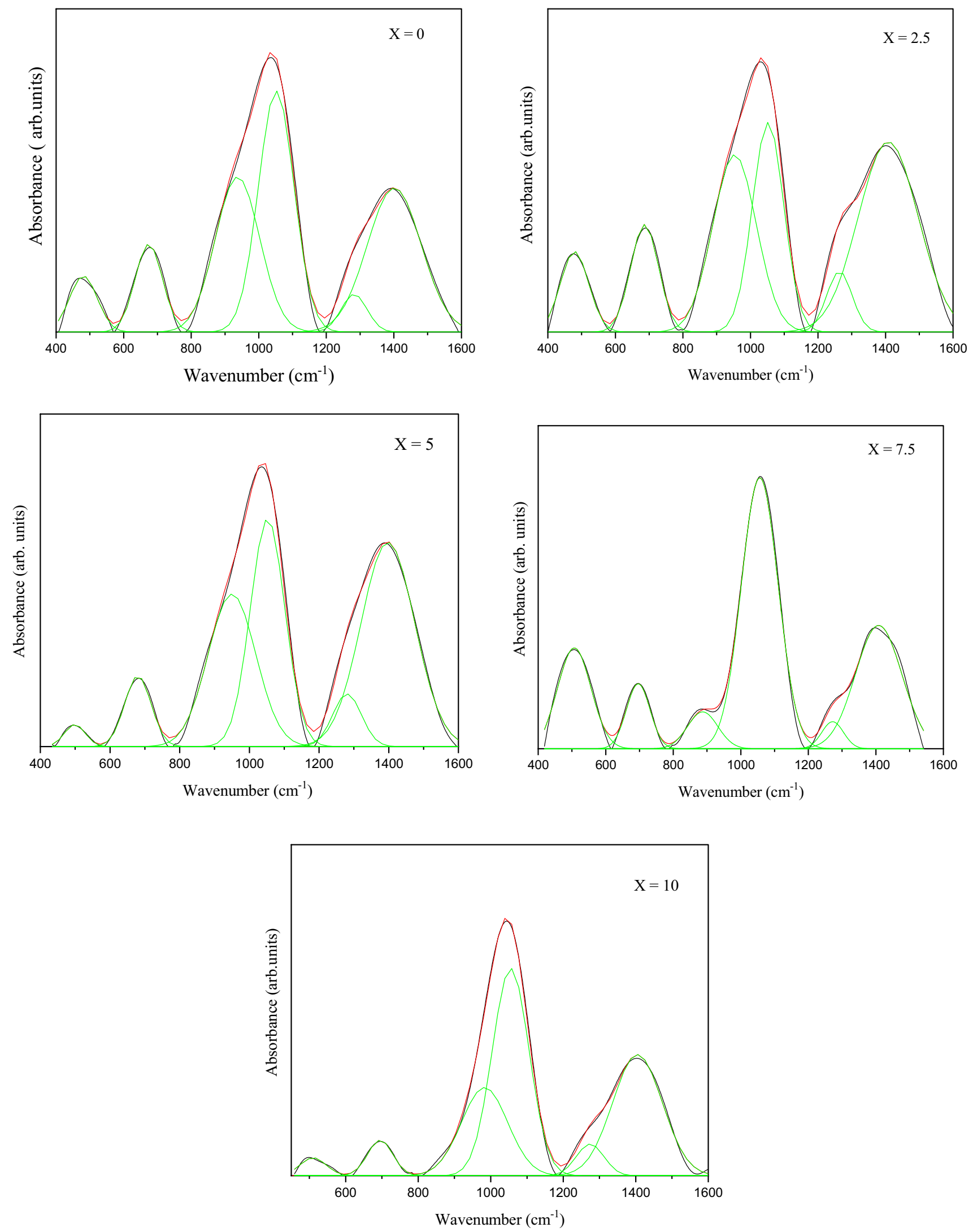

Fig. 4 De-convoluted FTIR spectra of $\mathrm{xBi}_{2} \mathrm{O}_{3}-(70-\mathrm{x}) \mathrm{B}_{2} \mathrm{O}_{3}-20 \mathrm{Li}_{2} \mathrm{O}-5 \mathrm{Sb}_{2} \mathrm{O}_{3}-5 \mathrm{ZnO}$ glasses 
Table 2 De-convoluted parameters of FT-IR spectra of $x \mathrm{Bi}_{2} \mathrm{O}_{3}-(70-\mathrm{x}) \mathrm{B}_{2} \mathrm{O}_{3}-20 \mathrm{Li}_{2} \mathrm{O}-5 \mathrm{Sb}_{2} \mathrm{O}_{3}-5 \mathrm{ZnO}$ glasses

\begin{tabular}{|c|c|c|c|c|c|c|c|c|c|c|c|c|c|c|}
\hline \multicolumn{3}{|l|}{$X=0$} & \multicolumn{3}{|l|}{$X=2.5$} & \multicolumn{3}{|l|}{$X=5$} & \multicolumn{3}{|l|}{$X=7.5$} & \multicolumn{3}{|l|}{$X=10$} \\
\hline $\mathrm{C}$ & W & A & $\mathrm{C}$ & W & A & $\mathrm{C}$ & W & A & $\mathrm{C}$ & W & A & $\mathrm{C}$ & W & A \\
\hline 468.02 & 82.22 & 0.40 & 479.09 & 83.62 & 1.18 & 498.90 & 59.48 & 0.11 & 506.86 & 96.35 & 0.96 & 510.10 & 71.35 & 0.24 \\
\hline 674.47 & 81.01 & 0.62 & 686.39 & 82.44 & 1.55 & 679.83 & 75.44 & 0.45 & 696.14 & 66.15 & 0.44 & 694.97 & 69.10 & 0.47 \\
\hline 937.25 & 130.81 & 1.42 & 953.00 & 128.87 & 3.99 & 950.04 & 136.34 & 1.76 & 887.06 & 86.97 & 0.32 & 983.09 & 127.24 & 2.13 \\
\hline 1051.85 & 105.54 & 1.87 & 1052.14 & 92.84 & 3.40 & 1052.29 & 99.32 & 1.92 & 1056.16 & 106.77 & 2.86 & 1054.97 & 101.26 & 3.98 \\
\hline 1282.33 & 76.44 & 0.62 & 1263.54 & 75.20 & 0.80 & 1280.41 & 82.29 & 0.37 & 1271.87 & 60.68 & 0.17 & 1274.13 & 76.20 & 0.46 \\
\hline 1401.36 & 159.64 & 2.38 & 1408.03 & 177.65 & 5.90 & 1397.65 & 154.16 & 2.67 & 1408.09 & 135.45 & 1.64 & 1404.77 & 136.70 & 3.13 \\
\hline
\end{tabular}

$C$ is component band centre $\left(\mathrm{cm}^{-1}\right)$ and $A$ is relative area (\%) of the component band

Table 3 Wavenumbers and band assignments of present glasses

\begin{tabular}{ll}
\hline Peak position & FTIR band assignment \\
\hline $468 \mathrm{~cm}^{-1}, 479 \mathrm{~cm}^{-1}$ & Attributed to the Li cation vibrations, attributed to the $\mathrm{Sb}_{2} \mathrm{O}_{3}$ bending vibrations [31] \\
$510 \mathrm{~cm}^{-1}$ & $\mathrm{Bi}-\mathrm{O}-\mathrm{Bi}$ vibrations of distorted [BiO6] octahedral units [26] \\
$674-694 \mathrm{~cm}^{-1}$ & $\mathrm{~B}-\mathrm{O}-\mathrm{B}$ bending vibrations, bending vibrations of $\mathrm{B}-\mathrm{O}-\mathrm{B}$ in $\mathrm{BO}_{3}$ units [29] [20] \\
$937-983 \mathrm{~cm}^{-1}$ & $\begin{array}{l}\text { Stretching vibrations of [BO } \\
\text { ] [26] }\end{array}$ \\
$1051-1056 \mathrm{~cm}-1$ & $\begin{array}{l}\text { Attributed to B-O stretching vibrations on } \mathrm{BO}_{4} \text { units form tri-, tetra-, and penta } \\
\text { borate groups [20,30] }\end{array}$ \\
$1263-1282 \mathrm{~cm}-1$ & $\begin{array}{l}\text { Assigned to B-O stretching vibrations of } \mathrm{BO}_{3} \text { units [20, 30] } \\
1397-1408 \mathrm{~cm}^{-1}\end{array}$ \\
& $\begin{array}{l}\text { Stretching vibrations of the } \mathrm{B}-\mathrm{O} \text { of trigonal }\left(\mathrm{BO}_{3}\right)^{3-} \text { units in metaborates, pyrobo- } \\
\text { rates, and orthoborates [20] }\end{array}$ \\
\hline
\end{tabular}

The calculated $\mathrm{N}_{3}$ and $\mathrm{N}_{4}$ values for present IR spectra were calculated. The variation of $\mathrm{N}_{3}$ and $\mathrm{N}_{4}$ values are illustrated in Fig. 5. From this it was observed that $\mathrm{N}_{3}$ values are decreasing whereas $\mathrm{N}_{4}$ values are increasing with $\mathrm{Bi}_{2} \mathrm{O}_{3}$ content. This result confirms the fact that when $\mathrm{Bi}_{2} \mathrm{O}_{3}$ is incorporated into the glass system, structural changes occur in the glass matrix and $\mathrm{BO}_{3}$ units transformed to $\mathrm{BO}_{4}$ units. In the present IR spectra the peak at $468 \mathrm{~cm}^{-1}$ is attributed to the Li cation vibrations and the $479 \mathrm{~cm}^{-1}$ is attributed to the $\mathrm{Sb}_{2} \mathrm{O}_{3}$ bending vibrations [31]. In the present IR study we observed a weak signal for $\mathrm{Li}_{2} \mathrm{O}$ and $\mathrm{ZnO}$ and this is due to the fact that the mol\% of above compounds were less participation in the glass network.

The Raman spectra of the samples $\mathrm{xBi}_{2} \mathrm{O}_{3}-(100-\mathrm{x})$ $\mathrm{B}_{2} \mathrm{O}_{3}-20 \mathrm{Li}_{2} \mathrm{O}-5 \mathrm{Sb}_{2} \mathrm{O}_{3}-5 \mathrm{ZnO}$ were studied at room temperature for spectral wave number ranging $200-2000 \mathrm{~cm}^{-1}$ and are presented in Fig. 6. The recorded Raman spectra are characterized by several broad bands which may be the mixture of more than one peak. The de-convoluted Raman spectra of typical glass samples presented in Fig. 7 and band assignments provided in the Table 4 . In the present spectra there are 3 major bands with wave number $300 \mathrm{~cm}^{-1}$, $490 \mathrm{~cm}^{-1}$ and $1300 \mathrm{~cm}^{-1}$ where as there are five less intense bands of wave number $400 \mathrm{~cm}^{-1} .1100 \mathrm{~cm}^{-1}, 1495 \mathrm{~cm}^{-1}$, $1655 \mathrm{~cm}^{-1}$ and $1840 \mathrm{~cm}^{-1}$.

The band in the range $297-304 \mathrm{~cm}^{-1}$ is attributed to bending vibrations of Zinc-Oxygen in tetrahedral $\mathrm{ZnO}_{4}$ units,

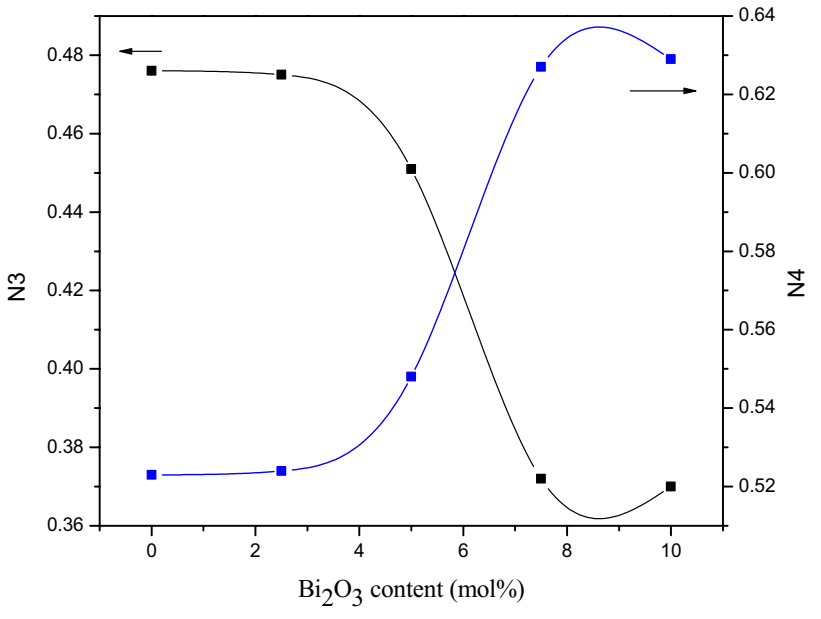

Fig. $5 \mathrm{~N} 3$ and $\mathrm{N} 4$ variation of present glasses

their bending modes and symmetrically stretching anionicmotion angularly constrained in cation-anion-cation configuration in $\mathrm{BiO}_{6}$ units. The bands in the range have similar intensity due to the constant $\mathrm{mol} \%$ of $\mathrm{ZnO}$ in the present glasses. This band was not observed in the IR spectra. The similar band in the range $400-491 \mathrm{~cm}^{-1}$ are assigned because of Bismuth-Oxygen and Bismuth-Oxygen-Bismuth vibrations in distorted $\mathrm{BiO}_{6}$ units, Bismuth-Oxygen stretching-vibrations in distorted linked $\mathrm{BiO}_{6}$ units 


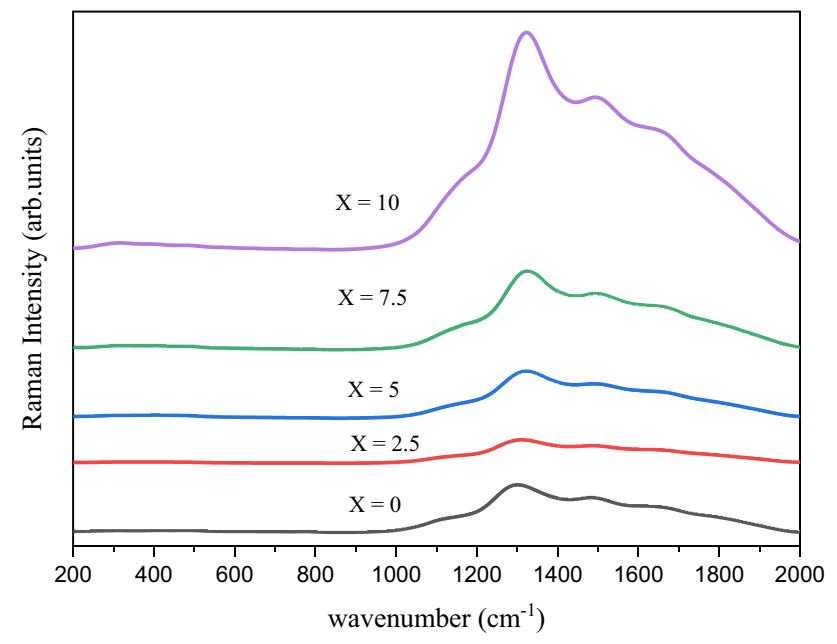

Fig. 6 Raman spectra of $\mathrm{xBi}_{2} \mathrm{O}_{3}-(70-\mathrm{x}) \mathrm{B}_{2} \mathrm{O}_{3}-20 \mathrm{Li}_{2} \mathrm{O}-5 \mathrm{Sb}_{2} \mathrm{O}_{3}-$ $5 \mathrm{ZnO}$ glasses

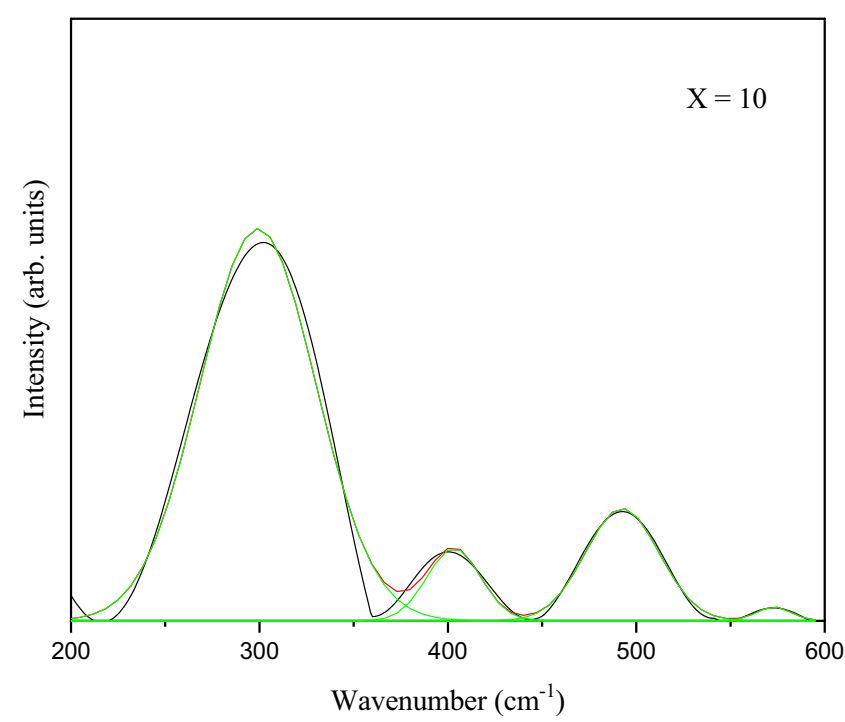

Fig. 7 De-convoluted Raman spectra of $X=10$ typical glass sample and similar vibrations of $\mathrm{Bi}-\mathrm{O}-/ \mathrm{Bi}-\mathrm{O}-\mathrm{Zn}$ [32]. The band around $1116-1137 \mathrm{~cm}^{-1}$ was observed and is attributed to the normal-vibrations of tri-borate, tetra-borate and pentaborate groups and Boron-Oxygen stretching-vibrations of the $\mathrm{BO}_{4}$ tetrahedra units with presence of di-borate groups. It has been observed that this band is shifting towards higher wavelengths when $\mathrm{Bi}_{2} \mathrm{O}_{3}$ content is increasing in the glass. This shifting confirms that there is a structural change in the galss network and the borate units are converting from $\mathrm{BO}_{3}$ to $\mathrm{BO}_{4}$ [32]. The band range $1297 \mathrm{~cm}^{-1}$ to $1319 \mathrm{~cm}^{-1}$ is due to the stretching-vibrations of $\mathrm{B}-\mathrm{O}$ bonds of pyroborate groups; vibrations are due to $\mathrm{BO}_{2}-\mathrm{O}$ triangularly-linked with $\mathrm{B}-\mathrm{O}$ units $[32,33]$. The Raman bands in the range 1495 to $1870 \mathrm{~cm}^{-1}$ is attributed to $\mathrm{BO}$ stretching-vibrations in $\mathrm{BO}_{3}$ triangular units due to various borate groups $[33,34]$.

\subsection{Density Model}

The ionic packing-ratio $\left(\mathrm{V}_{\mathrm{p}}\right)$ and density $(\rho)$ relation and is conveyed as [15]:

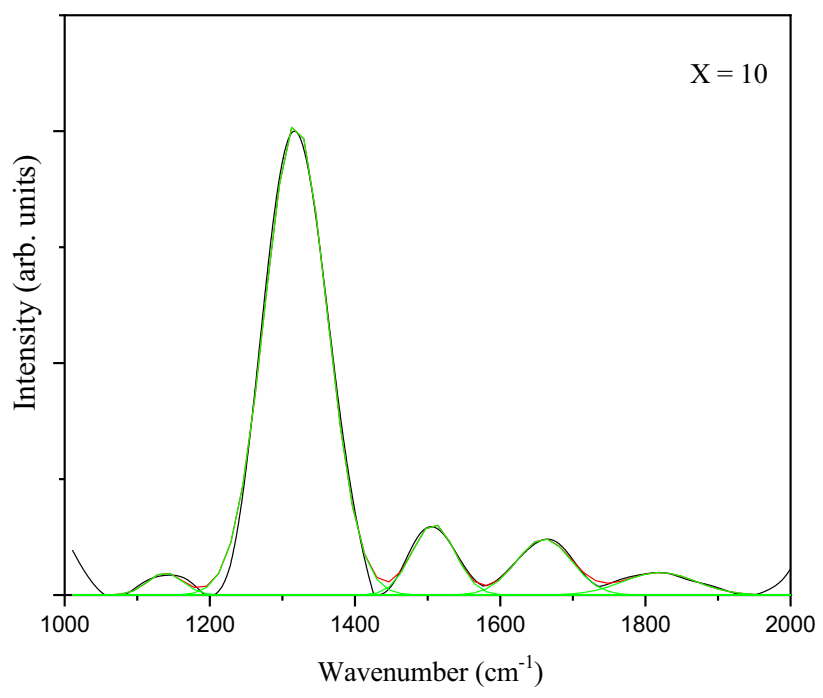

Table 4 Raman band assignments of present glasses

Peak position Raman band assignment

297-304 cm $\mathrm{cm}^{-1} \mathrm{Zn}-\mathrm{O}$ tetrahedral bending vibrations of $\mathrm{ZnO}_{4}$ units, bending modes of $\mathrm{ZnO}_{4}$ units and symmetric stretching anion motion in the angularly constrained cation-anion-cation configuration in the $\mathrm{BiO}_{6}$ units [32]

$400-492 \mathrm{~cm}^{-1} \quad$ Vibrations of $\mathrm{Bi}-\mathrm{O}$ and $\mathrm{Bi}-\mathrm{O}-\mathrm{Bi}$ in distorted $\mathrm{BiO} 6$ units, $\mathrm{Bi}-\mathrm{O}$ stretching vibrations in distorted linked $\mathrm{BiO} 6$ units and stretching vibrations of $\mathrm{Bi}-\mathrm{O}-/ \mathrm{Bi}-\mathrm{O}-\mathrm{Zn}$ [32]

$1116-1137 \mathrm{~cm}^{-1}$ attributed to the normal vibrations of tri-, tetra- and penta-borate groups and $\mathrm{B}-\mathrm{O}$ stretching vibrations of the $\mathrm{BO}_{4}$ tetrahedral [33]

1297-1319 $\mathrm{cm}^{-1}$ Stretching vibrations of $\mathrm{B}-\mathrm{O}$ bonds of pyroborate groups; vibrations due to $\mathrm{BO}_{2}-\mathrm{O}-$ triangles linked with $\mathrm{BO}$ units [32, 33]

$1495-1870 \mathrm{~cm}^{-1}$ BO stretching vibrations in $\mathrm{BO}_{3}$ triangular units $[33,34]$ 
Fig. 8 Relation between packing factor vs exp. density

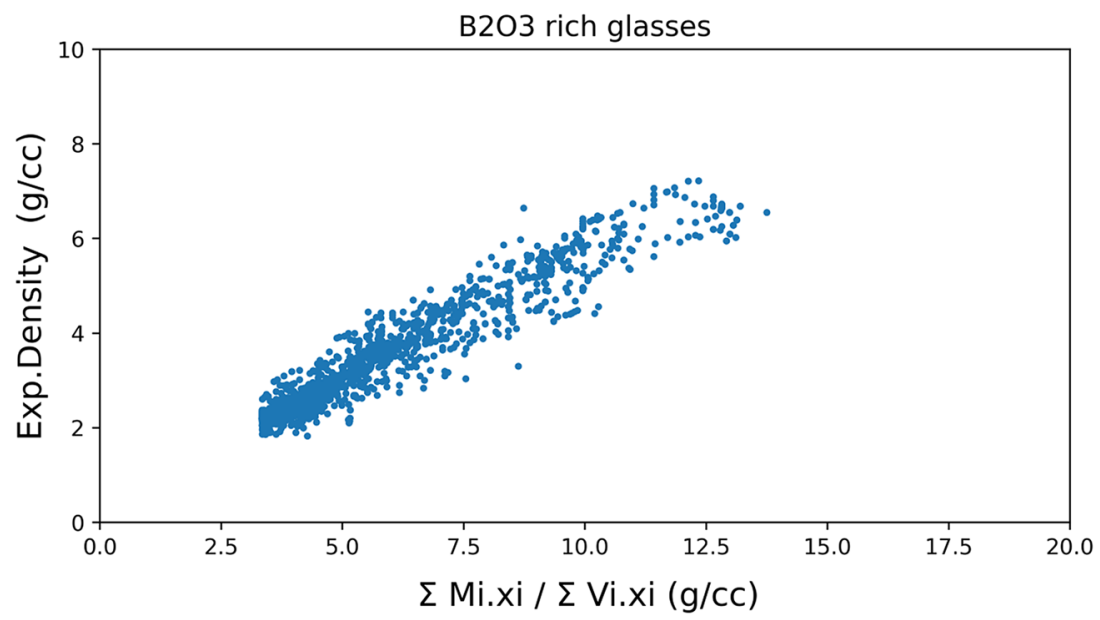

$V_{P}=\rho \cdot \frac{\sum\left(V_{i} \cdot x_{i}\right)}{\sum\left(M_{i} \cdot x_{i}\right)}$

$\mathrm{M}_{\mathrm{i}}=$ mole weight in gram per mole, $\mathrm{x}_{\mathrm{i}}=$ mole portion in mole percent, $\rho=$ glass Exp. Density (gram /cc), and $V_{i}=$ density parameter volume in meter $^{3} / \mathrm{mol}$ evaluated by [35]:

$V_{i}=\frac{4}{3} \pi \cdot N_{A} \cdot\left(X \cdot r_{M}^{3}+Y \cdot r_{O}^{3}\right)$

$\mathrm{N}_{\mathrm{A}}=$ Avogadro's number, $\mathrm{r}_{\mathrm{M}}, \mathrm{r}_{\mathrm{O}}$ are respective metallic and ionic radius of oxygen.

Inaba and Fujino's empirical model for predicting the glass density based on experimental results prevails as a viable method [36]. A $\pm 10 \%$ error was reported due to the ionic packing ratio proposed as constant by the authors. Inaba's formulation was based on the packing fraction which was also used by Makishima and Mackenzie [35] to theoretically compute Young's modulus using Pauling's ionic radii. It has been observed from previous study [16] there is no proper relation established between the exp.glass density to the fraction of volume to the molar weight i.e $\sum\left(V_{i} \cdot x_{i}\right) /\left(M_{i} \cdot x_{i}\right)$. here packing ratio assumed to be unchanged, the Eq. (4) would be given linear relation between dependent and independent variables. This concept was applied for all the ML models in the present study where $\left(M_{i} \cdot x_{i}\right) /\left(V_{i} \cdot x_{i}\right)$ Here $\mathrm{x}_{\mathrm{i}}$ becomes as an independent variable whereas experimental density holds as the depending y variable. Figure 8 illustrated the relation between the $\left(M_{i} \cdot x_{i}\right) /\left(V_{i} \cdot x_{i}\right)$ and glass measured density of $\mathrm{B}_{2} \mathrm{O}_{3}$ rich glasses along with prepared samples.

Recently Deng [13] studied the physical property such as density and mechanical properties of oxide glasses using machine learning tools, the parameters like density and elastic moduli of oxide glasses were predicted successfully and driven by using large dataset size of 24,858 and 8519 . The author claim that Lasso linear regression performs the best for prediction of density although to achieve the best $\mathrm{R}^{2}$ value around 0.7 with random forest is difficult only with the poisson's ratio.
More recently the Artificial density model was developed [16] based on the chemical composition and exp. Density using large data set 6630 oxide glass samples. In this study authors claim gradient decent, RF regression and ANNs successfully fit the glass data.

The above literature claim that Machine learning techniques required the large data to run the algorithm techniques to predict glass properties. In the present study the density prediction of prepared sample $\mathrm{xBi}_{2} \mathrm{O}_{3}-(70-\mathrm{x})$ $\mathrm{B}_{2} \mathrm{O}_{3}-20 \mathrm{Li}_{2} \mathrm{O}-5 \mathrm{Sb}_{2} \mathrm{O}_{3}-5 \mathrm{ZnO}(\mathrm{x}=0,2.5,5,7.5$ and $10 \mathrm{~mol} \%)$ determined by training the large data set of $2000 \mathrm{~B}_{2} \mathrm{O}_{3}$ glass samples using different ML techniques.

\subsection{Machine Learning Models}

\subsubsection{Gradient Descent}

The gradient descent algorithm (GD) employs the input dependent and independent variables along with slope derived from pre-processing the glass data using linear regression analysis. For linear regression, the glass data is split into 0.25 and 0.75 as test and train sizes and the resulting output slope ' $\mathrm{m}$ ' obtained is taken as input for executing gradient decent. This 'pre-processing' is run distinctly for glass formers and combined glass datasets. For arriving at an optimum learning rate and epoch, exhaustive analysis was implemented which ultimately concluded in optimized gradient descent results.

The GD algorithmic equation is built and modifying curve equations are followed by:

$$
\begin{aligned}
& D_{m}=\frac{1}{n} \sum_{i=0}^{n} 2\left(y_{i}-\left(m x_{i}+c\right)\right)\left(-x_{i}\right) \\
& D_{m}=\frac{-2}{n} \sum_{i=0}^{n} x_{i}\left(y_{i}-\bar{y}_{i}\right)
\end{aligned}
$$


Fig. 9 Gradient decent density prediction of present data set

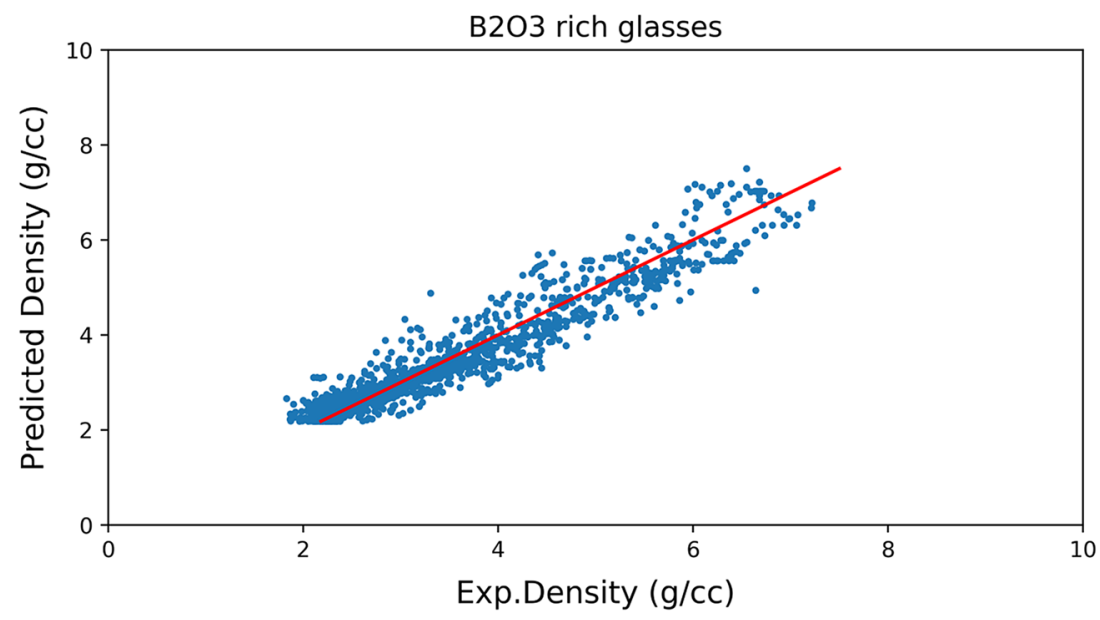

$D_{m}=$ partial derive with respect to slope and $n$ where $n$ is total number of data points.

Similarly, the partial derive regarding intercept c i.e., $D_{c}$. and it is computed by Chain rule.

$D_{c}=\frac{-2}{n} \sum_{i=0}^{n}\left(y_{i}-\bar{y}_{i}\right)$

The values of ' $\mathrm{m}$ ' and 'c' are revised using:

$m=m-L \times D_{m}$

$c=c-L \times D_{c}$

With ' $\mathrm{L}$ ' is learning rate

The cost may be calculated using power chain rule and it given by

$\frac{1}{2 m} \sum_{i=1}^{m}\left(h_{\theta}\left(x_{i}\right)-y_{i}\right)^{2}$

Using above algorithm we can predict the densities using calculated slope $\mathrm{m}$ and intercepts at zero with minimum cost function.

Figure 9 clarifies the plot between the predicted and measured density of $\mathrm{B}_{2} \mathrm{O}_{3}$ rich glasses and prepared glasses. The computed errors like RMSE, mean square error, $\mathrm{R}^{2}$ and cost values were presented in Table 5. For the both the dataset the learning value is taken as constant 0.001 . The cost function obtained in this algorithm is 0.018 which show the good performance of the algorithm. The $\mathrm{R}^{2}$ value obtained in the study 0.897 Shows good results from the gradient decent algorithm which trains to the glass data and predicts density values. The experimental and predicted density values for the present glasses presented in the Table 1 .

\subsubsection{Artificial Neural Networks}

In this technique, a single layer ANN employing activation functions like Identity, ReLU, Sigmoid and Tanh are used to train the glass datasets which were split as 0.2 and 0.8 for test and train respectively. To obtain optimization for the present algorithm, numerous iterations were run for varying hidden layer sizes with solver function taken as 'lbfgs'.

Deng [13] used various AI-techniques to predict glass properties like density and elastic moduli for a large combined-dataset of $\sim 25,000$ datapoints and obtained an $\mathrm{R}^{2}$ of 0.942 for ANN prediction of glass densities. Effendy et al. [11] also obtained an $\mathrm{R}^{2}$ of $0.99942-1.00$ for glass composition $\mathrm{yBi}_{2} \mathrm{O}_{3}-(1-\mathrm{y}) \mathrm{TeO}_{2}$. The high $\mathrm{R}^{2}$ can be attributed to the very small size of the dataset. The results of ANNs gave satisfactory prediction performance with an $\mathrm{R}^{2}$ of 0.84 using Tanh activation function in a previous study [15] employing a large dataset in case of combined glasses. The binary glass prediction to possess more accuracy than other glass refractive index prediction. The results of this distinctive study also produced the best results as compared to the previous literature available employing large glass datasets, thus enabling the findings of this work to future glass research
Table 5 Error analysis of various ML models

\begin{tabular}{lllllll}
\hline Error & Gradient decent & Random forest & \multicolumn{4}{l}{ Artificial neural network } \\
\cline { 4 - 6 } & & & Sigmoid & ReLu & Identity & tanh \\
\hline MSE & 0.141 & 0.069 & 0.2720 & 0.299 & 0.230 & 0.229 \\
MAE & 0.030 & 0.263 & 0.099 & 0.100 & 0.104 & 0.100 \\
$\mathrm{R}^{2}$ & 0.897 & 0.983 & 0.910 & 0.920 & 0.944 & 0.950 \\
\hline
\end{tabular}




\section{Sigmoid}

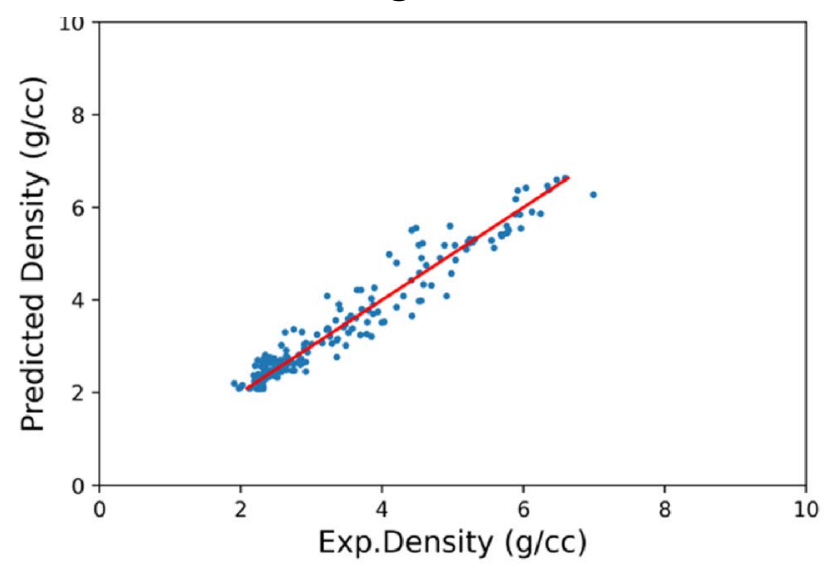

Identity

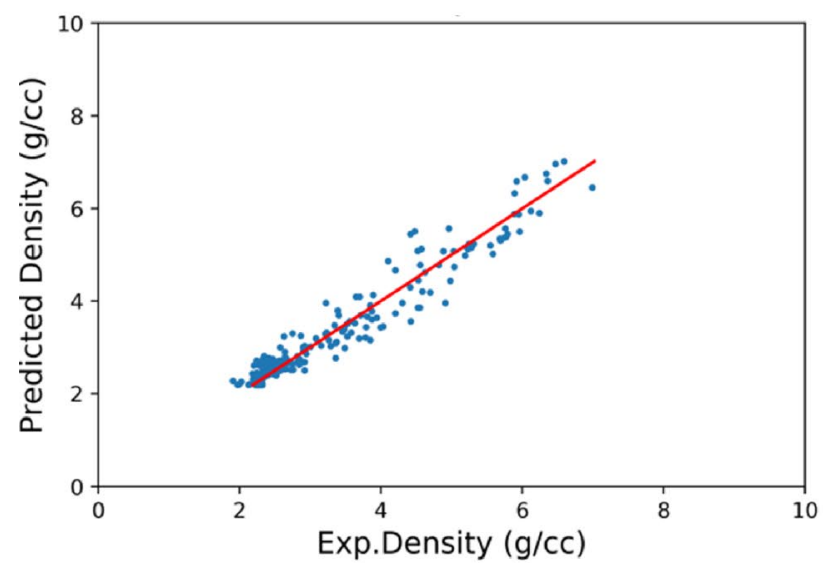

ReLu

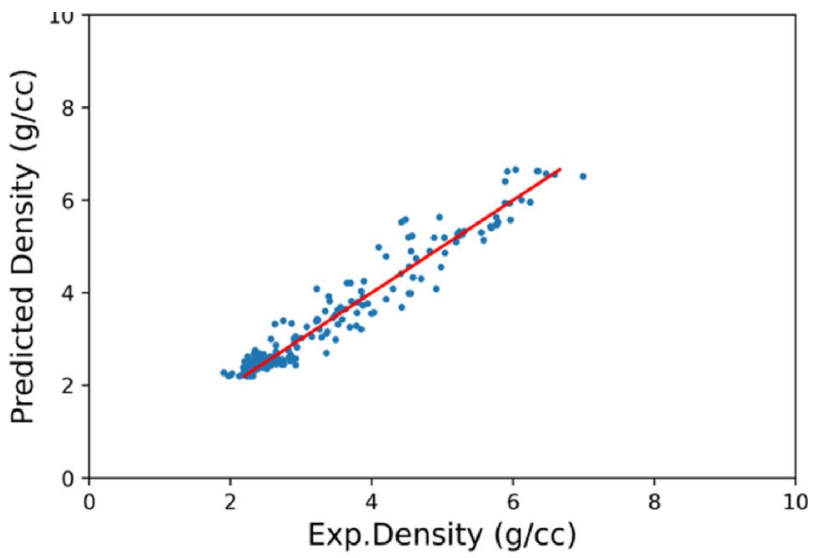

$\tanh$

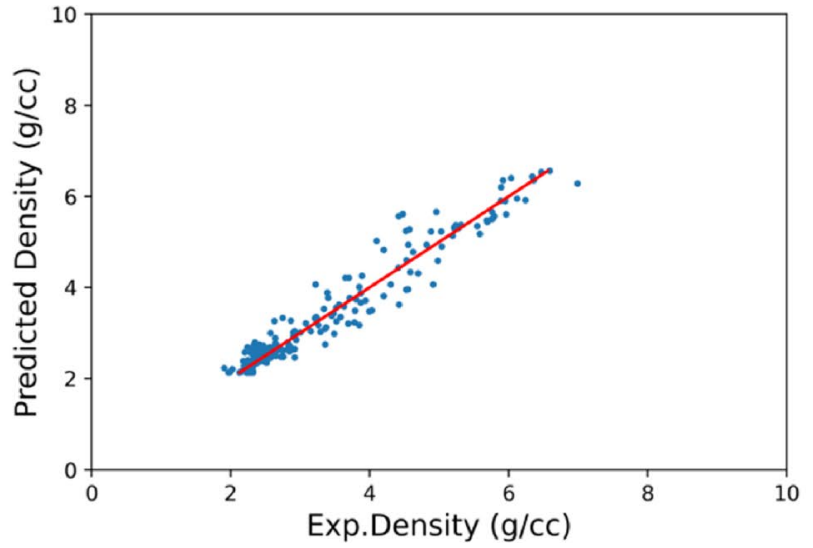

Fig. 10 ANN density prediction with different activation functions

Fig. 11 Random forest regression fitting curve

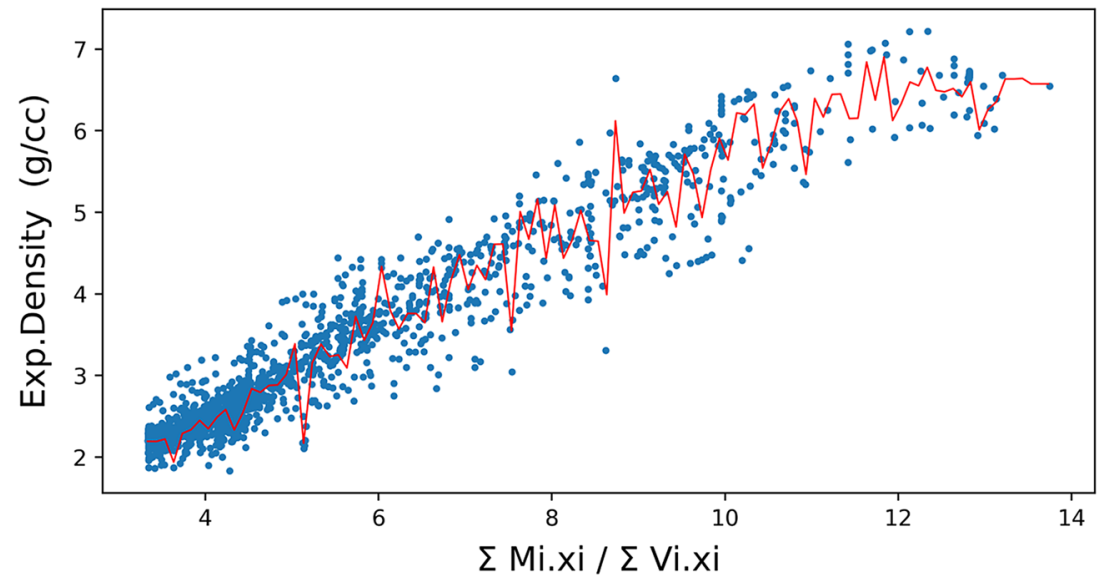

employing Artificial Intelligence. Previous studies [13-16] also proved ANNs to perform better than other algorithms for prediction using glass datasets.

Figure 10 shows the variation of predicted and exp. densities with different activation functions of the present data set.
The programmable output errors were tabulated in Table 5 and it has been observed that tanh activation function found to dominating in the density prediction of present glasses. Compare to the gradient decent model the ANNs is better to fit the dataset. The obtained $\mathrm{R}^{2}$ of 0.950 which is much 
Fig. 12 Random forest regression density prediction

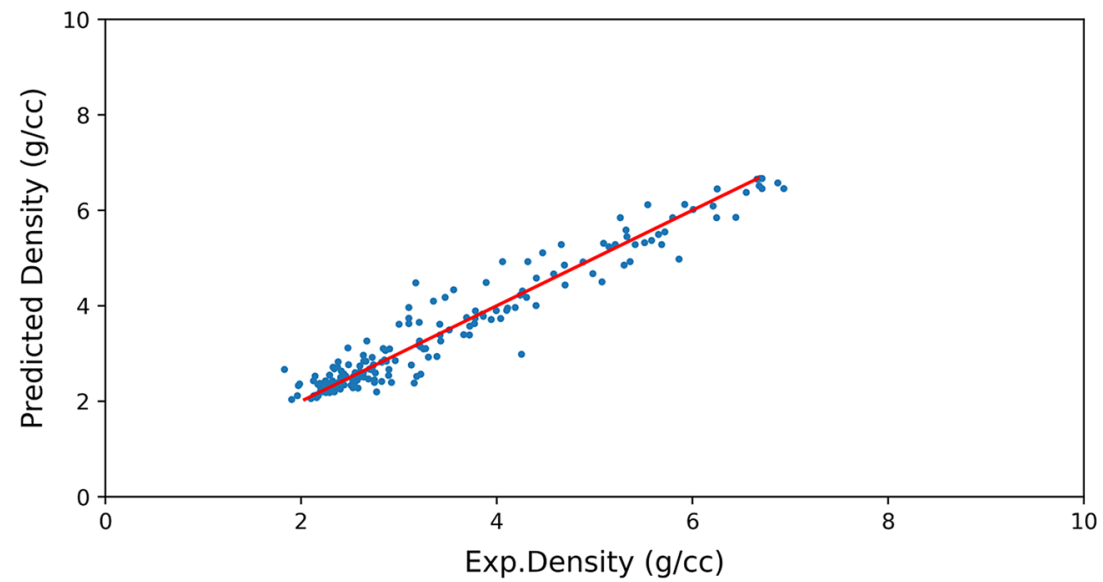

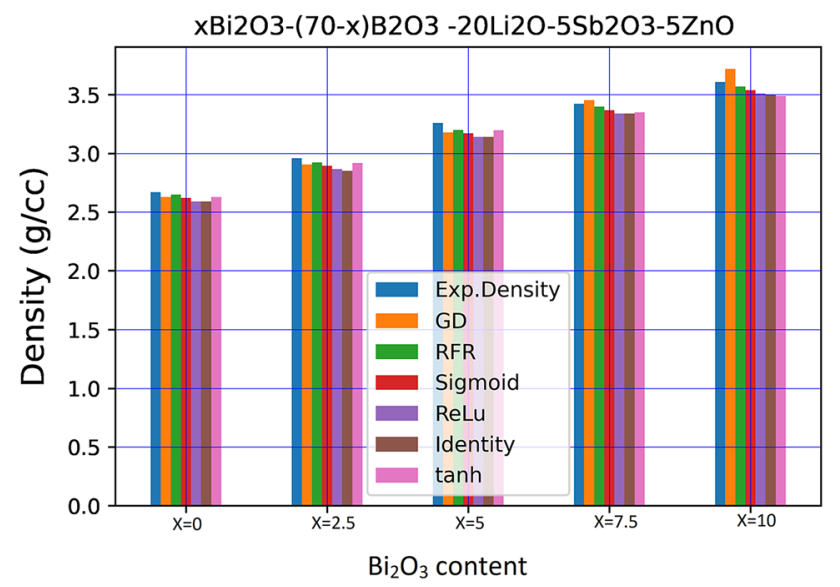

Fig. 13 Predicted Vs Experimental density of various ML Models

better than gradient decent and conclude that artificial neural network is predicting glass density successfully.

\subsubsection{Random Forest Regression}

After data pre-processing, the dataset was split as testing and training sets with the first in ratio 0.2 for all the glass datasets and the remaining 0.8 for training the data. Tuning of hyperparameters like n_estimators and random_state functions was performed for optimizing the algorithm. Relative to the individual dataset sizes, we arrived at the maximum possible n_estimators value after thorough analysis.

The RF fitting stimulated line for dependent and independent variables is presented in Fig. 11. The density prediction from the RF regression analysis is shown in Fig. 12 and the calculated various errors are tabulated in Table 5. Form the results of Fig. 12 it has been conclude that the RF egression is fitting the glass data perfectly with the maximum $R^{2}$ values 0.983 which is also shows the glass data is successfully train with $\mathrm{RF}$ algorithm compared to gradient and
ANN functions. Summarizing the prediction performance, the densities values in the case of random forest regression are very close the experimental density followed by ANN and gradient decent. Figure 13 represents that the RFR is suitable for predicting the glass density comparably Linear Regression and ANNs for the present data set.

Very recently [13] employing APF to predict glass densities obtained $R^{2}$ values as high as 0.62 for the combined glass dataset versus 0.985 obtained in the present study employing APF in density prediction. Previous research [15], the glass data was analyzed using RFR algorithm which resulted in an $\mathrm{R}^{2}$ of 0.989 for a very large size combined glass dataset. The present results surpass the previous works which can be accredited to the more logical Rigid Unit Packing Parameter concept incorporated in the RFR algorithm.

\section{Conclusions}

Bismuth borate zinc glass system $\mathrm{xBi}_{2} \mathrm{O}_{3}-(70-\mathrm{x})$ $\mathrm{B}_{2} \mathrm{O}_{3}-20 \mathrm{Li}_{2} \mathrm{O}-5 \mathrm{Sb}_{2} \mathrm{O}_{3}-5 \mathrm{ZnO}$ were prepared and experimental density correlated with glass composition by incorporating machine learning techniques to predict the glass densities. The following are the major results form the above study.

- The glass composition $\mathrm{xBi}_{2} \mathrm{O}_{3}-(70-\mathrm{x}) \mathrm{B}_{2} \mathrm{O}_{3}-20 \mathrm{Li}_{2} \mathrm{O}-$ $5 \mathrm{Sb}_{2} \mathrm{O}_{3}-5 \mathrm{ZnO}$ prepared and measured the experimental density using Archimedes principle.

- The experimental densities of the studied glasses improves with increasing $\mathrm{Bi}_{2} \mathrm{O}_{3}$ content 2.671 to 3.610 $(\mathrm{g} / \mathrm{cc})$. In bismuth doped samples the oxygen ions are converted from $\mathrm{BO}_{3}$ structural units to $\mathrm{BO}_{4}$ structural units, the $\mathrm{BO}_{4}$ units are heavier when compared to $\mathrm{BO}_{3}$ units that increase the density of the glass

- A wide range of 2000 distinct $\mathrm{B}_{2} \mathrm{O}_{3}$ rich glasses configurations was sourced from reputed journals with their 
laboratory tested density values to train on various ML models.

- The input variable (Mi.xi) / (Vi.xi) and measured densities were incorporated to ML models to perform glass density prediction which shows good agreement with the testing data.

- As comparison with Linear regression and ANNs, forest regression shows better performance that was confirms from the result that the value $\mathrm{R}^{2}$ is high as 0.983 .

- The density values derived from the random forest regression are similar to the experimental values due to higher $\mathrm{R}^{2}$ values.

- Predicting the densities through Tanh as the activating function result in the best prediction performance in Artificial neural networks.

- The different neural networks were developed for the prediction of the densities but here ANNs were got to be best result in predicting glass densities with Tanh being the optimum activating function compared to identity.

- There is a shift in wavenumbers form 674 to $694 \mathrm{~cm}^{-1}$ and has increasing with $\mathrm{Bi}_{2} \mathrm{O}_{3}$ content which is attributed to Boro-Oxy-Boro chain in $\left[\mathrm{BO}_{3}\right]$ units [22]. This may be created by electrostatic field of the strong polarizability of $\mathrm{Bi}^{2+}$ ions.

- When $\mathrm{Bi}_{2} \mathrm{O}_{3}$ content increases and red shift in the IR band range 1056 to $1051 \mathrm{~cm}^{-1}$ observed which is attributed to the transformation of structural units from $\mathrm{BO}_{3}$ to $\mathrm{BO}_{4}$.

- The Raman band ranging $297-304 \mathrm{~cm}^{-1}$ is attributed to $\mathrm{Zn}-\mathrm{O}$ tetrahedral bending-vibrations of $\mathrm{ZnO}_{4}$ units.

- In Raman band range $1116-1137 \mathrm{~cm}^{-1}$ is shifting towards higher wavelengths when $\mathrm{Bi}_{2} \mathrm{O}_{3}$ content increasing in the glass. This shifting is conforms that there is structural changes in the glass metarix and borate units converting from $\mathrm{BO}_{3}$ to $\mathrm{BO}_{4}$ units.

Acknowledgements The authors of this manuscript thankful to Prof. Karuna Sagar, Head Department of Physics, College of Science, OU for providing laboratory facility and Late Prof. Syed Rahman, former head, Department of Physics, OU who passed away recently due to COVID-19 for his outstanding contribution and suggestions.

\section{References}

1. F. Borsa, D.R. Torgeson, S. Martin, H. Patel, Phys. Rev. B 46, 795 (1992). https://doi.org/10.1103/PhysRevB.46.795

2. Y. Dimitriev, A.C. Wright, V. Mihailova, E. Gattef, C.A. Guy, An $\mathrm{X}$-ray diffraction study of bismuthate glasses. J. Mater. Sci. Lett. 14, 347-350 (1995). https://doi.org/10.1007/BF00592146

3. Y. Cheng, H. Xiao, W. Guo, W. Guo, Structure and crystallization kinetics of $\mathrm{Bi}_{2} \mathrm{O}_{3}-\mathrm{B}_{2} \mathrm{O}_{3}$ glasses. Thermochim. Acta 444, 173 (2006). https://doi.org/10.1016/j.tca.2006.03.016
4. H. Zheng, J.D. Mackenzie, Phys. Rev. B 38, 7166 (1988). https:// doi.org/10.1103/PhysRevB.38.7166

5. A. Madhu, B. Eraiah, N. Srinatha, Infrared Phys. Technol. 107, 103300 (2020). https://doi.org/10.1016/j.infrared.2020.103300

6. D.W. Hall, M.A. Newhouse, N.F. Borrelli, W.H. Dumbaugh, D. Weidman, Nonlinear optical susceptibilities of high-index glasse. Appl. Phys. Lett. 54, 1293 (1989). https://doi.org/10.1063/1. 100697

7. M. Onishi, M. Kyoto, M. Watanabe, Properties of Bi-Pb-Sr-Ca$\mathrm{Cu}-\mathrm{O}$ glass-ceramic fibers formed by glass-drawing method. Jpn. J. Appl. Phys. 30, L988 (1991). https://doi.org/10.1143/JJAP.30. L988

8. A. Madhu, B. Eraiah, N. Srinatha, J. Luminescence 221, 117080 (2020). https://doi.org/10.1016/j.jlumin.2020.117080

9. H. Doweidar, Y.B. Saddeek, FTIR and ultrasonic investigations on modified bismuth borate glasses. J. Non-Cryst. Solids $\mathbf{3 5 5}$, 348-354 (2009). https://doi.org/10.1016/j.jnoncrysol.2008.12.008

10. Y.B. Saddeek, Ultrasonic study and physical properties of some borate glasses. Mater. Chem. Phys. 83, 222-228 (2004). https:// doi.org/10.1016/j.matchemphys.2003.09.051

11. A. Fluegel, Global model for calculating room-temperature glass density from the composition. J. Am. Ceram. Soc. 90(8), 26222625 (2007). https://doi.org/10.1111/j.1551-2916.2007.01751.x

12. M.L. Huggins, J.M. Stevels, Comparison of two equations for calculation of densities of glasses from their compositions. J. Am. Ceram. Soc. 37(10), 474-479 (1954). https://doi.org/10.1111/j. 1151-2916.1954.tb13979.x

13. B. Deng, Machine learning on density and elastic property of oxide glasses driven by large dataset. J. Non Cryst. Solids 529, 119768 (2020). https://doi.org/10.1016/j.jnoncrysol.2019.119768

14. S.K. Ahmmad, M. Hamraj, S.T.U. Ahmed, N. Jabeen, physical properties of ordinary Portland cements. Bikaner (2020). https:// doi.org/10.1063/5.0001386

15. M.A. Marzouk, S.M. Abo-Naf, H.A. Zayed, N.S. Hassan, Photoluminescence and semiconducting behavior of $\mathrm{Fe} \mathrm{Co}, \mathrm{Ni}$ and $\mathrm{Cu}$ implanted in heavy metal oxide glasses. J. Market. Res. 5(3), 226-233 (2016). https://doi.org/10.1016/j.jmrt.2015.11.003

16. S.K. Ahmmad, N. Jabeen, S.T.U. Ahmed, S.A. Ahmed, S. Rahman, Ceram. Int. 47, 7946-7956 (2021). https://doi.org/10.1016/j. ceramint.2020.11.144

17. Y. Shi, A. Tandia, B. Deng, S.R. Elliott, M. Bauchy, Acta Mater. 195, 252-262 (2020). https://doi.org/10.1016/j.actamat.2020.05. 047

18. M. Kurudirek, N. Chutithanapanon, R. Laopaiboon, C. Yenchai, C. Bootjomchai, Effect of $\mathrm{Bi}_{2} \mathrm{O}_{3}$ on gamma ray shielding and structural properties of borosilicate glasses recycled from high pressure sodium lamp glass. J. Alloys Compd. 745, 355-364 (2018). https://doi.org/10.1016/j.jallcom.2018.02.158

19. H.D. Shashikala, N.K. Udayashankar, Influence of Fe $3+$ ions on optical, structural, thermal andmechanical properties of $\mathrm{Li}_{2} \mathrm{O}$ $\mathrm{Na}_{2} \mathrm{O}-\mathrm{K}_{2} \mathrm{O}-\mathrm{ZnO}-\mathrm{B}_{2} \mathrm{O}_{3}$ based glass system. Ceram. Int. (October) (2019). https://doi.org/10.1016/j.ceramint.2019.10.269

20. S. Rani, S. Sanghi, N. Ahlawat, A. Agarwal, Influence of $\mathrm{Bi}_{2} \mathrm{O}_{3}$ on thermal, structural and dielectric properties of lithium zinc bismuth borate glasses. J. Alloys Compd. 597, 110-118 (2014). https://doi.org/10.1016/j.jallcom.2014.01.211

21. P. Pascuta, G. Borodi, E. Culea, J. Non-Cryst. Solids 354, 5475 (2008). https://doi.org/10.1016/j.jnoncrysol.2008.09.010

22. M. Bala, S. Agrohiya, S. Dahiya, A. Ohlan, R. Punia, A.S. Maan, J. Mol. Struct. (2020). https://doi.org/10.1016/j.molstruc. 2020. 128589

23. M. Bala, S. Agrohiya, S. Dahiya, A. Ohlan, R. Punia, A.S. Maan, J. Mol. Struct. 1234, 130160 (2021). https://doi.org/10.1016/j. molstruc.2021.130160

24. S. Dahiya, R. Punia, A.S. Maan, Structural and other physical properties of lithium doped bismuth zinc vanadate semiconducting 
glassy system. J. Mol. Struct. 1079, 189-193 (2015). https://doi. org/10.1016/j.molstruc.2014.09.047

25. N. Berwal, S. Dhankhar, P. Sharma, R.S. Kundu, R. Punia, N. Kishore, Physical, structural and optical characterization of silicate modified bismuth-borate-tellurite glasses. J. Mol. Struct. 1127, 636 (2017). https://doi.org/10.1016/j.molstruc.2016.08.033

26. Y. Cheng, H. Xiao, W. Guo, W. Guo, Structure and crystallization kinetics of $\mathrm{Bi}_{2} \mathrm{O}_{3}-\mathrm{B}_{2} \mathrm{O}_{3}$ glasses. Thermochim. Acta 444, 173-178 (2006)

27. M.E. Lines, A.E. Miller, K. Nassau, K.B. Lyons, J. Non-Cryst, Solids 89, 163-180 (1987). https://doi.org/10.1016/S00223093(87)80330-7

28. P. Kaur, K.J. Singh, S. Thakur, M. Kurudirek, M.M. Rafiei, Structural investigations and nuclear radiation shielding ability of bismuth lithium antimony borate glasses. J. Phys. Chem. Solids. (2020). https://doi.org/10.1016/j.jpcs.2020.109812

29. M.I. Sayyed, H.O. Tekin, M.M. Taki, M.H.A. Mhareb, O. Agar, E. Sakar, K.M. Kaky, $\mathrm{Bi}_{2} \mathrm{O}_{3}$ - B2O3- ZnO-BaO-Li2O glass system for gamma ray shielding applications. Optik (2019). https://doi. org/10.1016/j.ijleo.2019.163525

30. M. Toderas, S. Filip, I. Ardelean, J. Opt. Electron. Adv. Mater. 8, $1121(2006)$

31. G. Lakshminarayana, S.O. Bakib, K.M. Kakya, M.I. Sayyedc, H.O. Tekind, A. Lirae, I.V. Kitykf, M.A. Mahdia, Investigation of structural, thermal properties and shielding parameters for multicomponent borate glasses for gamma and neutron radiation shielding applications. J. Non-Crystalline Solids 471(1), 222-237 (2017). https://doi.org/10.1016/j.jnoncrysol.2017.06. 001

32. B. Shanmugavelu, V.V.R.K. Kumar, Thermal, structural and electrical studies of bismuth Zinc borate glasses. Solid State Sci. 20, 59-64 (2013). https://doi.org/10.1016/j.solidstatesciences.2013. 03.008

33. S. Stalina, A. Edukondalua, M.A. Sameea, C. Srinivasud, S. Rahman, Physical and optical investigations of $\mathrm{Bi}_{2} \mathrm{O}_{3}-\mathrm{TeO}_{2}-\mathrm{B}_{2} \mathrm{O}_{3}-\mathrm{GeO}_{2}$ glasses. Mater. Res. Express (2020). https://doi.org/10.1088/2053-1591/ab689c

34. M. Purnima, S. Stalin, A. Edukondalu, M.A. Samee, S.K. Ahmmad, S. Rahman, Spectroscopic studies on $\mathrm{Li}_{2} \mathrm{O}-\mathrm{MgO}-\mathrm{Bi}_{2} \mathrm{O}_{3}-$ $\mathrm{B}_{2} \mathrm{O}_{3}$ glasses. Chin. J. Phys. 66, 517-526 (2020)

35. A. Makishima, J.D. Mackenzie, J. Non-Cryst. Solids 12, 35-45 (1973). https://doi.org/10.1016/0022-3093(73)90053-7

36. S. Inaba, S. Fujino, J. Am. Ceram. Soc. 93, 217-220 (2010). https://doi.org/10.1111/j.1551-2916.2009.03363.x

Publisher's Note Springer Nature remains neutral with regard to jurisdictional claims in published maps and institutional affiliations. 